\title{
Prediction of the risk of surgical complications in patients undergoing monopolar transurethral resection of bladder tumour - a prospective multicentre observational study
}

\author{
Sławomir Poletajew ${ }^{1}$, Wojciech Krajewski², Dominika Gajewska³, Joanna Sondka-Migdalska4, \\ Michał Borowik ${ }^{5}$, Paweł Buraczyński ${ }^{6}$, Mateusz Dzięgała², Marcin Łykowski ${ }^{1}$, Maciej Przudzik ${ }^{5}$, \\ Andrzej Tukiendorf ${ }^{7}$, Rafał Woźniak ${ }^{8}$, Krzysztof Bar ${ }^{6}$, Zbigniew Jabłonowski ${ }^{4}$, Marek Roslan $^{5}$, \\ Marcin Słojewski ${ }^{3}$, Romuald Zdrojowy ${ }^{2}$, Piotr Radziszewski ${ }^{1}$, Konrad Dziobek ${ }^{9}$
}

\author{
${ }^{1}$ Department of General, Oncological, and Functional Urology, Medical University \\ of Warsaw, Warsaw, Poland \\ ${ }^{2}$ Department of Urology and Oncological Urology, Wroclaw Medical University, \\ Wroclaw, Poland \\ ${ }^{3}$ Department of Urology and Urological Oncology, Pomeranian Medical University, \\ Szczecin, Poland \\ ${ }^{4} 1^{\text {st }}$ Department of Urology, Medical University of Lodz, Lodz, Poland \\ ${ }^{5}$ Department of Urology, University of Warmia and Mazury, Olsztyn, Poland \\ ${ }^{6}$ Department of Urology and Urologic Oncology, Medical University of Lublin, Lublin, \\ Poland \\ ${ }^{7}$ Social Medicine Department, Wroclaw Medical University, Wroclaw, Poland \\ ${ }^{8}$ Chair of Statistics and Econometrics, Faculty of Economic Sciences, University \\ of Warsaw, Warsaw, Poland \\ ${ }^{9}$ Maria Sklodowska-Curie Memorial Cancer Centre and Institute of Oncology, \\ Krakow Branch, Krakow, Poland
}

Submitted: 24 February 2019

Accepted: 21 April 2019

Arch Med Sci 2020; 16 (4): 863-870

DOI: https://doi.org/10.5114/aoms.2019.88430

Copyright (c) 2019 Termedia \& Banach

\begin{abstract}
Introduction: The aim of the study was to identify predictors of surgical complications of transurethral resection of bladder tumour (TURBT).

Material and methods: We prospectively recruited 983 consecutive patients undergoing TURBT within 7 months in six academic institutions. All patients were followed up from the surgery up to 30 days postoperatively with at least one telephone contact at the end of the observation. The primary study endpoint was any intra- or postoperative surgical complication. For the identification of predictors of complications, univariate and multivariate logistic regression models were used. Trial registration: ClinicalTrials.gov (NCT03029663). Registered 24 January 2017.

Results: Surgical complications were noticed in 228 (23.2\%) patients, including $83(8.4 \%)$ patients with more than one complication and 33 cases of Clavien-Dindo grade 3 complications (3.3\%). The most common in-hospital complications were bleeding $(n=139,14.1 \%)$ and bladder perforation ( $n=46,4.7 \%)$. In a multivariate analysis, nicotine use, high ASA score, and the presence of high-grade tumour were the most significant predictors of high-grade complications. The stage of the disease was the strongest predictor of bleeding, while the presence of muscle in the specimen and resident surgeon were the strongest predictors for bladder perforation.

Conclusions: TURBT poses a significant risk of surgical complications, the majority of which are of low grade.
\end{abstract}

Key words: bladder cancer, transurethral resection of bladder tumour, postoperative complications, intraoperative complications, residency.
Corresponding author: Wojciech Krajewski PhD Department of Urology and Oncological Urology Wrocław Medical University 213 Borowska St 50-556 Wrocław, Poland Phone: +48691510609 E-mail: wk@softstar.pl 
S. Poletajew, W. Krajewski, D. Gajewska, J. Sondka-Migdalska, M. Borowik, P. Buraczyński, M. Dzięgała, M. Łykowski, M. Przudzik, A. Tukiendorf, R. Woźniak, K. Bar, Z. Jabłonowski, M. Roslan, M. Słojewski, R. Zdrojowy, P. Radziszewski, K. Dziobek

\section{Introduction}

Transurethral resection of bladder tumour (TURBT) is one the most commonly performed urological procedure [1, 2]. Despite most bladder cancers being non-muscle invasive (NMIBC), TURBT can be a challenging operation due to high tumour burden, intraoperative bleeding, difficult tumour location, or other factors. Moreover, the experience of surgeon plays a key role in the oncological quality of TURBT [3]. The limited available data indicate that TURBT is a morbid procedure with a risk of surgical complications of 5-20\% [4-9]. While these numbers are high in contemporary urology, profound discussion of surgical technique and possible complications is a mandatory part of patient counselling. Unfortunately, up to date, predictors of TURBT complications have not been not adequately identified. This precludes any individual calculation.

The aim of the study was to identify predictors of surgical complications of TURBT.

\section{Material and methods}

\section{Patients}

This prospective, multicentre, cross-sectional, observational study enrolled 983 consecutive patients undergoing TURBT in six academic institutions between January 2017 and July 2017. The mean age of the cohort was 68.8 years (range: 18-98), and the male-to-female ratio was $3: 1$. Inclusion criteria were as follows: age $\geq 18$ years, resection of bladder tumour, sterile urine preoperatively or ongoing directed antibiotic therapy at the time of surgery, and signed, informed consent. The investigating urologists explained the purpose of the study to each patient, as well as the protection of participant confidentiality and the participants' freedom to drop out at any time. The study recruited patients with both primary and recurrent bladder tumours. Patients with primary tumours constituted $34.8 \%$ of the cohort. In $55 \%$ of cases a solitary tumour was resected. The size of the (largest) tumour was $>3 \mathrm{~cm}$ in $28.9 \%$ of cases and the detrusor muscle was infiltrated in $13.1 \%$ of cases. Preoperative micro- or macroscopic haematuria was noticed in $34.2 \%$ of patients. Detailed baseline patient characteristics are presented in Table I. The vast majority of patients underwent monopolar TURBT. Patients undergoing restaging resection, cold-cup biopsy, fulguration only, or cystoscopy only were excluded from the analysis.

\section{Methods}

The primary study endpoint was any intra- or postoperative surgical complication. A full list of clinical events defined as potentially related to
TURBT in the study is presented in Table II. All patients were followed-up for 30 days postoperatively with at least one telephone contact at the end of the observation. The variables tested for prediction of complications were as follows: patient basic characteristics (sex, age, nicotine use, height, weight, body mass index - BMI, American Society of Anaesthesiologists score - ASA score, presence of haematuria and/or pyuria), oncological data (stage and grade of bladder cancer, presence of concomitant carcinoma in situ, number of previous TURBTs, recurrence rate, previous intravesical therapy), and surgical details (number and size of tumours, surgeon experience, surgery time, type of anaesthesia, postoperative catheterisation time, postoperative hospitalisation time, presence of muscularis propria in surgical specimen). All study data were collected by each study site in a dedicated uniform electronic form. Before the study initiation, the protocol was registered within ClinicalTrials.gov (NCT03029663) and was approved by the Institutional Review Board.

\section{Statistical analysis}

For binary outcomes, univariate and multivariate logistic regressions were applied. The statistical influence was expressed by a classical odds ratio (OR) together with a 95\% confidence interval $(95 \% \mathrm{Cl})$ and a $p$-value. The computation was performed in the R platform [10].

\section{Results}

Surgical complications were observed in 228 (23.2\%) patients, including 83 (8.4\%) patients with more than one complication. When comparing baseline data between patients without and with complications, the latter had larger tumours (2.6 vs. $1.8 \mathrm{~cm}, p<0.01)$, longer surgery time (36.2 vs. $26.4 \mathrm{~min}, p<0.01$ ), longer postoperative catheterisation time (64.0 vs. $25.1 \mathrm{~h}, p<0.01)$, and longer postoperative hospitalisation time (1.9 vs. 1.3 days, $p<0.01$ ).

Table III presents a detailed list of complications noticed within the study. The most common in-hospital complications were postoperative bleeding defined subjectively as presence of the blood in the urine in the postoperative period $(n=139,14.1 \%)$ and intraoperative bladder perforation ( $n=46,4.7 \%)$. There were 33 cases of Clavien-Dindo grade $\geq 3$ complications in 32 patients (3.3\%), namely: re-interventions due to bleeding $(n=17,1.7 \%)$, bladder perforation $(n=10$, $1.0 \%)$, or urinary retention $(n=3,0.3 \%)$; acute coronary syndrome ( $n=1,1.0 \%)$; deaths due to pulmonary embolism ( $n=1,1.0 \%)$; and myocardial infarction ( $n=1,1.0 \%$ ). After discharge, the most common complications were lower urinary tract 
Table I. Baseline characteristics of the study cohort

\begin{tabular}{|c|c|}
\hline Clinical characteristic & Prevalence \\
\hline \multicolumn{2}{|l|}{ Gender: } \\
\hline Male & $737(75 \%)$ \\
\hline Female & $246(25 \%)$ \\
\hline \multicolumn{2}{|l|}{ Age [years]: } \\
\hline$<65$ & $320(32.6 \%)$ \\
\hline $65-70$ & $226(23 \%)$ \\
\hline $70-75$ & $175(17.8 \%)$ \\
\hline$>75$ & $262(26.6 \%)$ \\
\hline \multicolumn{2}{|l|}{ ASA: } \\
\hline 1 & $146(14.9 \%)$ \\
\hline 2 & $605(61.5 \%)$ \\
\hline 3 & $219(22.2 \%)$ \\
\hline 4 & $3(0.3 \%)$ \\
\hline Missing & $10(1 \%)$ \\
\hline \multicolumn{2}{|l|}{ BMI [kg/m²]: } \\
\hline$\leq 25$ & $307(31.2 \%)$ \\
\hline $25.1-30$ & $424(43.2 \%)$ \\
\hline $30.1-35$ & $184(18.7 \%)$ \\
\hline$>35$ & $55(5.6 \%)$ \\
\hline Missing & $13(1.3 \%)$ \\
\hline \multicolumn{2}{|l|}{ Nicotine use: } \\
\hline Yes & $395(40.2 \%)$ \\
\hline No & $578(58.8 \%)$ \\
\hline Missing & $10(1 \%)$ \\
\hline \multicolumn{2}{|l|}{ Prior TURBT: } \\
\hline 0 & $342(34.8 \%)$ \\
\hline 1 & $276(28.1 \%)$ \\
\hline 2 & $146(14.7 \%)$ \\
\hline$\geq 3$ & $215(22 \%)$ \\
\hline Missing & $4(0.4 \%)$ \\
\hline \multicolumn{2}{|c|}{ Recurrence rate [rec/year]: } \\
\hline 0 (primary tumour) & $342(34.8 \%)$ \\
\hline$\leq 1$ & $535(54.4 \%)$ \\
\hline$>1$ & $102(10.4 \%)$ \\
\hline Missing & $4(0.4 \%)$ \\
\hline \multicolumn{2}{|c|}{ Previous intravesical chemotherapy: } \\
\hline Yes & $39(4 \%)$ \\
\hline No & $943(95.9 \%)$ \\
\hline Missing & $1(0.1 \%)$ \\
\hline \multicolumn{2}{|c|}{ Previous intravesical BCG immunotherapy: } \\
\hline Yes & $103(10.5 \%)$ \\
\hline No & $878(89.3 \%)$ \\
\hline Missing & $2(0.2 \%)$ \\
\hline \multicolumn{2}{|c|}{ Preoperative haematuria: } \\
\hline Yes & $337(34.2 \%)$ \\
\hline No & $646(67.7 \%)$ \\
\hline
\end{tabular}

\begin{tabular}{|lc|}
\hline Clinical characteristic & Prevalence \\
\hline Preoperative pyuria: & \\
\hline Yes & $299(30.4 \%)$ \\
\hline No & $684(69.6 \%)$ \\
\hline Missing & $3(0.3 \%)$ \\
\hline
\end{tabular}

Level of training of primary surgeon:

\begin{tabular}{ll}
\hline Specialist & $547(55.6 \%)$ \\
\hline Resident & $436(44.4 \%)$
\end{tabular}

Number of tumours:

1

$2166(16.9 \%)$

$\geq 3 \quad 258(26.2 \%)$

Missing $17(1.7 \%)$

Type of anaesthesia:

\begin{tabular}{ll}
\hline Spinal & $712(72.4 \%)$ \\
\hline
\end{tabular}

Intratracheal general $132(13.4 \%)$

Totally intravenous general 94 (9.6\%)

Missing $45(4.6 \%)$

Tumour size $[\mathrm{cm}]$ :

\begin{tabular}{lc}
\hline$<1$ & $238(24.2 \%)$ \\
\hline $1-3$ & $431(43.8 \%)$ \\
\hline$>3$ & $284(28.9 \%)$ \\
\hline Missing & $30(3.1 \%)$
\end{tabular}

Length of hospitalisation [days]:

\begin{tabular}{lc}
\hline$\leq 1$ & $752(76.5 \%)$ \\
\hline 2 & $91(9.3 \%)$ \\
\hline 2 & $135(13.7 \%)$ \\
\hline Missing & $5(0.5 \%)$
\end{tabular}

Length of catheterisation [h]:

\begin{tabular}{lc}
\hline$\leq 24$ & $767(78.1 \%)$ \\
\hline $25-48$ & $74(7.5 \%)$ \\
\hline$>48$ & $132(13.4 \%)$ \\
\hline Missing & $10(1 \%)$
\end{tabular}

Tumour stage $(T)$ :

$0 \quad 130(13.2 \%)$

a $472(48 \%)$

$206(21.1 \%)$

$2129(13.1 \%)$

PUNLMP $8(0.8 \%)$

Cis $11(1.1 \%)$

Missing $27(2.7 \%)$

High-grade tumour:

\begin{tabular}{lc}
\hline Yes & $360(36.6 \%)$ \\
\hline No & $588(59.8 \%)$ \\
\hline Missing & $35(3.6 \%)$ \\
\hline Concomitant Cis: & $62(6.3 \%)$ \\
\hline Yes & $890(90.5 \%)$ \\
\hline No & $31(3.2 \%)$ \\
\hline
\end{tabular}

ASA - American Society of Anaesthesiologists score, BCG - Bacillus-Calmette Guerin, BMI - body mass index, Cis - carcinoma in situ, TURBT - transurethral resection of the bladder tumour. 
S. Poletajew, W. Krajewski, D. Gajewska, J. Sondka-Migdalska, M. Borowik, P. Buraczyński, M. Dzięgała, M. Łykowski, M. Przudzik, A. Tukiendorf, R. Woźniak, K. Bar, Z. Jabłonowski, M. Roslan, M. Słojewski, R. Zdrojowy, P. Radziszewski, K. Dziobek

Table II. Clinical events defined as potentially related to TURBT in the study

\begin{tabular}{|c|}
\hline Clinical events \\
\hline Intraoperative events (alphabetic order): \\
\hline Bladder perforation, extraperitoneal \\
\hline Bladder perforation, intraperitoneal \\
\hline Intravesical gas explosion \\
\hline Injury to bladder mucosa (not related to resection) \\
\hline Injury to ureteral orifice \\
\hline Injury to urethra (including "false" passage) \\
\hline Obturator nerve reflex \\
\hline Others \\
\hline Postoperative events (alphabetic order): \\
\hline Acute urinary retention (after catheter removal) \\
\hline Bleeding, requiring blood transfusion \\
\hline Bleeding, requiring conservative treatment \\
\hline Bleeding, requiring surgical intervention \\
\hline Cardiac arrhythmia \\
\hline Death \\
\hline Deep venous thrombosis \\
\hline Electrolyte imbalance \\
\hline Fever \\
\hline Lower urinary tract symptoms \\
\hline Myocardial infarction \\
\hline Orchitis/epididymitis \\
\hline Pain \\
\hline Post-TUR syndrome \\
\hline Prostatitis \\
\hline Pulmonary embolism \\
\hline Renal colic \\
\hline Renal function deterioration \\
\hline Respiratory tract infection \\
\hline Stroke \\
\hline Others \\
\hline Urinary incontinence \\
\hline Urinary tract infection \\
\hline
\end{tabular}

symptoms not related to infection ( $n=68,6.9 \%)$, symptomatic urinary tract infections $(n=61$, $6.2 \%)$, haematuria $(n=53,5.4 \%)$, and urinary retention $(n=6,0.6 \%)$, with $6(0.6 \%)$ patients requiring reintervention and no Clavien-Dindo grade $\geq 4$ complications.

In a multivariate analysis, high ASA score, nicotine use and the presence of high-grade tumour were the most significant predictors of high-grade complications. The stage of the disease was the strongest predictor of bleeding, while the presence of muscle in the specimen and the resident surgeon were the strongest predictors for bladder perforation. Detailed results of the uni- and multivariate logistic regression analyses between
Table III. Detailed list of complications noted within the study

\begin{tabular}{|c|c|}
\hline Complication & $\begin{array}{l}\text { Number of } \\
\text { patients () }\end{array}$ \\
\hline \multicolumn{2}{|l|}{ Intraoperative complications: } \\
\hline Bladder perforation & $46(4.7)$ \\
\hline Significant obturator nerve reflex & $20(2.0)$ \\
\hline Gas explosion & $4(0.4)$ \\
\hline Urethral injury and/or false passage & $4(0.4)$ \\
\hline \multicolumn{2}{|c|}{ Postoperative complications during hospitalization: } \\
\hline Haematuria & $139(14.1)$ \\
\hline Lower urinary tract symptoms & $24(2.4)$ \\
\hline Bleeding requiring re-interventions & $17(1.7)$ \\
\hline Urinary retention & $10(1.0)$ \\
\hline Bleeding requiring transfusion & $7(0.7)$ \\
\hline Bladder tamponade & $6(0.6)$ \\
\hline Urinary tract infection & $4(0.4)$ \\
\hline Fever & $3(0.3)$ \\
\hline Acute coronary syndrome & $1(0.1)$ \\
\hline Death due to pulmonary embolism & $1(0.1)$ \\
\hline Death due to myocardial infarction & $1(0.1)$ \\
\hline Heart failure acute exacerbation & $1(0.1)$ \\
\hline Patient catheter self-extraction & $1(0.1)$ \\
\hline Renal colic & $1(0.1)$ \\
\hline \multicolumn{2}{|c|}{ Postoperative complications after discharge: } \\
\hline $\begin{array}{l}\text { Lower urinary tract symptoms not } \\
\text { related to infection }\end{array}$ & $68(6.9)$ \\
\hline Urinary tract infection & $61(6.2)$ \\
\hline Haematuria & $53(5.4)$ \\
\hline Urinary retention & $6(0.6)$ \\
\hline Urinary incontinence & $3(0.3)$ \\
\hline Impotence & $2(0.2)$ \\
\hline Retrograde ejaculation & $1(0.1)$ \\
\hline Bleeding requiring re-interventions & $1(0.1)$ \\
\hline $\begin{array}{l}\text { Bladder perforation requiring re- } \\
\text { interventions }\end{array}$ & $1(0.1)$ \\
\hline Walking problems & $1(0.1)$ \\
\hline Bladder tamponade & $1(0.1)$ \\
\hline
\end{tabular}

clinical factors and endpoints are presented in Tables IV and V, respectively. Only statistically significant correlations are presented.

\section{Discussion}

While TURBT is one the most commonly performed urological procedure, literature data on its safety is scarce. The few studies published in the past enrolled limited numbers of patients, had a retrospective nature, or did not lead to any practical conclusions. We prospectively analysed complications of TURBT, finding that the surgery was associated with a relatively high risk of com- 
plications. However, the clear majority of them were of low grade and required only conservative management. For the most common high-grade complications, the most important predictors were high ASA score, nicotine use, high cancer stage and grade, presence of muscularis propria in a specimen, and the resident surgeon. Based on our findings, we believe the rate of complications can be further reduced by proper preoperative identification of high-risk patients, who should be operated on with extra caution by an experienced surgeon.

Bladder perforation is probably the most important complication from a clinical point of view. First, it may require laparotomy and cystorrhaphy in cases of intraperitoneal perforation, while all patients usually require prolonged bladder catheterisation and antibiotic prophylaxis, which have their consequences [11]. Second, bladder perforation influences the oncological outcomes by precluding immediate postoperative intravesical chemotherapy instillation and increasing the risk of extravesical cancer spread [12-14]. In our study, we found that resident surgeon and the presence of muscle in a specimen were factors independently associated with over three-fold higher risk of bladder perforation. For this reason, we strongly believe that complex cases should be faced only by experienced endourologists. Moreover, experienced surgeons are more likely to perform a complete TURBT with a muscle in a spec-

Table IV. Univariate logistic regressions analysis (statistically significant results only)

\begin{tabular}{|c|c|c|c|c|}
\hline Clinical event & Predictive factor & OR & $95 \% \mathrm{Cl}$ & $P$-value \\
\hline \multirow{7}{*}{$\begin{array}{l}\text { Complication during } \\
\text { hospital stay }\end{array}$} & Recurrence rate & 0.75 & $0.58-0.96$ & 0.021 \\
\hline & Preoperative haematuria & 2.02 & $1.49-2.73$ & $<0.001$ \\
\hline & Preoperative pyuria & 1.46 & $1.07-1.99$ & 0.018 \\
\hline & ASA score & 1.5 & $1.18-1.92$ & 0.001 \\
\hline & Tumour size & 1.32 & $1.22-1.43$ & $<0.001$ \\
\hline & Surgery time & 1.03 & $1.03-1.04$ & $<0.001$ \\
\hline & High-grade tumour & 1.81 & $1.33-2.45$ & $<0.001$ \\
\hline \multirow{8}{*}{$\begin{array}{l}\text { Any Clavien-Dindo } \\
\geq 3 \text { complication }\end{array}$} & Nicotine use & 2.15 & $1.07-4.31$ & 0.031 \\
\hline & $\mathrm{BMI}>30 \mathrm{~kg} / \mathrm{m}^{2}$ & 1.06 & $1.01-1.12$ & 0.023 \\
\hline & Preoperative haematuria & 2.22 & $1.12-4.42$ & 0.023 \\
\hline & ASA score & 2.36 & $1.33-4.2$ & 0.003 \\
\hline & Number of tumours & 1.12 & $1.04-1.21$ & 0.002 \\
\hline & Tumour size & 1.29 & $1.11-1.49$ & $<0.001$ \\
\hline & Surgery time & 1.02 & $1.01-1.04$ & $<0.001$ \\
\hline & High-grade tumour & 2.74 & $1.35-5.54$ & 0.005 \\
\hline \multirow{4}{*}{$\begin{array}{l}\text { Complication } \\
\text { during } 30 \text {-day } \\
\text { postoperative period }\end{array}$} & ASA score & 1.44 & $1.1-1.87$ & 0.007 \\
\hline & Number of tumours & 1.07 & $1.01-1.13$ & 0.015 \\
\hline & Tumour size & 1.12 & $1.03-1.22$ & 0.009 \\
\hline & Surgery time & 1.0099 & $1.0021-1.0177$ & 0.012 \\
\hline \multirow[t]{8}{*}{ Bleeding } & Gender & 1.65 & $1.05-2.59$ & 0.03 \\
\hline & Preoperative BCG immunotherapy & 0.48 & $0.23-1.01$ & 0.054 \\
\hline & Preoperative haematuria & 1.91 & $1.33-2.75$ & $<0.001$ \\
\hline & ASA score & 1.66 & $1.23-2.23$ & $<0.001$ \\
\hline & Tumour size & 1.4 & $1.28-1.53$ & $<0.001$ \\
\hline & Surgery time & 1.03 & $1.02-1.04$ & $<0.001$ \\
\hline & Tumour stage & 1.91 & $1.54-2.39$ & $<0.001$ \\
\hline & Muscle in specimen & 2.14 & $1.39-3.31$ & $<0.001$ \\
\hline \multirow[t]{5}{*}{ Bladder perforation } & Nicotine use & 1.89 & $1.03-3.44$ & 0.039 \\
\hline & Resident operator & 2.23 & $1.21-4.11$ & 0.01 \\
\hline & Tumour size & 1.16 & $1.01-1.33$ & 0.04 \\
\hline & Surgery time & 1.03 & $1.02-1.04$ & $<0.001$ \\
\hline & Muscle in specimen & 3.53 & $1.48-8.44$ & 0.005 \\
\hline
\end{tabular}

OR - odds ratio, 95\% Cl - 95\% confidence interval, ASA - American Society of Anaesthesiologists score, BCG - Bacillus-Calmette Guerin, $B M I$ - body mass index. 
S. Poletajew, W. Krajewski, D. Gajewska, J. Sondka-Migdalska, M. Borowik, P. Buraczyński, M. Dzięgała, M. Łykowski, M. Przudzik, A. Tukiendorf, R. Woźniak, K. Bar, Z. Jabłonowski, M. Roslan, M. Słojewski, R. Zdrojowy, P. Radziszewski, K. Dziobek

Table V. Multivariate logistic regressions analysis (statistically significant results only)

\begin{tabular}{|c|c|c|c|c|}
\hline Clinical event & Predictive factor & OR & $95 \% \mathrm{Cl}$ & $P$-value \\
\hline \multirow{4}{*}{$\begin{array}{l}\text { Complication during } \\
\text { hospital stay }\end{array}$} & Preoperative haematuria & 1.5 & $1.07-2.08$ & 0.017 \\
\hline & ASA score & 1.34 & $1.03-1.74$ & 0.03 \\
\hline & Surgery time & 1.03 & $1.02-1.04$ & $<0.001$ \\
\hline & High grade tumour & 1.53 & $1.11-2.12$ & 0.01 \\
\hline \multirow{6}{*}{$\begin{array}{l}\text { Any Clavien- } \\
\text { Dindo grade } \geq 3 \\
\text { complication }\end{array}$} & Nicotine use & 2.26 & $1.07-4.81$ & 0.034 \\
\hline & $\mathrm{BMI}>30 \mathrm{~kg} / \mathrm{m}^{2}$ & 1.07 & $1.01-1.13$ & 0.032 \\
\hline & ASA score & 2.64 & $1.38-5.04$ & 0.003 \\
\hline & Number of tumours & 1.15 & $1.06-1.24$ & $<0.001$ \\
\hline & Surgery time & 1.02 & $1-1.03$ & 0.007 \\
\hline & High grade tumour & 2.88 & $1.3-6.37$ & 0.009 \\
\hline \multirow{3}{*}{$\begin{array}{l}\text { Complication during } \\
\text { 30-day postoperative } \\
\text { period }\end{array}$} & ASA score & 1.48 & $1.12-1.95$ & 0.005 \\
\hline & Number of tumours & 1.07 & $1.02-1.14$ & 0.012 \\
\hline & Tumour size & 1.11 & $1.01-1.2$ & 0.022 \\
\hline \multirow[t]{2}{*}{ Bleeding } & Preoperative BCG immunotherapy & 1.2 & $1.11-1.31$ & 0.008 \\
\hline & Tumour stage & 1.83 & $1.32-2.54$ & $<0.001$ \\
\hline \multirow[t]{4}{*}{ Bladder perforation } & Resident operator & 3.19 & $1.39-7.29$ & 0.006 \\
\hline & Tumour size & 0.78 & $0.62-0.97$ & 0.029 \\
\hline & Surgery time & 1.02 & $1-1.03$ & 0.015 \\
\hline & Muscle in specimen & 3.4 & $1.11-10.38$ & 0.032 \\
\hline
\end{tabular}

OR - odds ratio, 95\% Cl - 95\% confidence interval, ASA - American Society of Anaesthesiologists score, BCG - Bacillus-Calmette Guerin, $B M I$ - body mass index.

imen [15-17]. This leads to reduced recurrence rate at first follow-up cystoscopy in NMIBC cases and shorter time to cystectomy in MIBC cases [15, $16,18]$. On the other hand, in stage Ta tumours, the muscularis propria is not mandatory for completeness of TURBT and proper staging, which was confirmed by Shoshany et al. [19]. These cases seem more appropriate for residents at their learning curve. Finally, we discussed only clinically significant perforations, while radiological signs of perforation can be present in as many as $58 \%$ of asymptomatic patients after TURBT [20]. Bleeding was the most common complication observed in our analysis. It affected almost one sixth of patients in the early postoperative period or after discharge. However, the severity of symptoms ranged from patients treated conservatively to others who needed bladder irrigation, blood transfusion, or surgical reintervention. In contrast to our findings, Hollenbeck et al. observed haematuria only in $2.1 \%$ of cases in a group of 21,515 TURBTs. At the same time, 30-day mortality of $1.3 \%$ was reported [21]. We suppose these differences resulted from the retrospective design of the Hollenbeck study, which hampered precise and adequate data collection on the postoperative course. In the recent observational study by Bansal et al., transient haematuria was observed in $26 \%$ of patients, and another $6 \%$ of patients re- quired blood transfusion or reintervention due to bleeding after TURBT [5]. A modifiable risk factor of perioperative bleeding is coagulopathy. However, according to available data, it is not justified to discontinue antiplatelet monotherapy with acetylsalicylic acid in patients scheduled for TURBT because it does not reduce the bleeding risk significantly but may increase the cardiovascular risk [22]. Carmignani et al. showed that TURBT is feasible and relatively safe also in patients receiving dual antiplatelet therapy [23]. However, the risk of bleeding and clot retention may be increased in patients receiving anticoagulation therapy [24].

In our study, significant obturator nerve reflex was observed in $2 \%$ of cases. There are many possible methods to decrease this risk under debate [25]. One of them is the use of bipolar resection instead of monopolar. In 2016, Cui et al. and Zhao et al. published two independent meta-analyses on the efficacy and safety of monopolar and bipolar TURBT. Both research groups analysed data from eight trials, concluding that bipolar resection is associated with fewer complications compared to monopolar TURBT. However, this conclusion is not universal and differs in detail even between these two meta-analyses. While surgery time, catheterisation time, and blood loss are reduced with bipolar resection, data on the risk of obturator nerve reflex, bladder perforation, or transfu- 
sion rate are heterogenous $[26,27]$. Moreover, in recent studies published by Balci et al. and Ozer et al. the risk of obturator nerve reflex and bladder perforation is even higher during bipolar than monopolar TURBT [28, 29], while the difference in overall safety was not noticed. In our study, the choice between monopolar and bipolar resection was made by the surgeon. Yet, because of the fact that the majority of procedures were monopolar, the issue was not analysed as a risk factor of complications. Another method to reduce the risk of obturator nerve reflex and bladder perforation in cases of tumours located on later bladder wall is obturator nerve block. While this method is effective [30], its routine implementation in all cases does not seem feasible. In the present study, obturator nerve block was performed only upon request of the operating urologist.

The most important limitation of our study is a short-term follow-up, aimed only at the identification of surgical complications. Because TURBT is an oncological procedure, one can be interested also in the impact of complications on recurrence-free survival, which was not assessed within the study. Another issue is no information regarding surgical technique, especially concerning the use of mono- and bipolar resection or en-bloc and in-fractions resection. While the first issue was discussed before, the latter should also be interpreted with caution because Zhang et al. recently observed no advantage of en bloc resection over conventional TURBT in terms of safety [4]. For grading of complications, we adopted the Clavien-Dindo classification, which is now the most accurate one. However, this classification was developed for postoperative complications only, while there is no analogous classification for intraoperative complications. Additionally, catheterisation time and hospitalisation time can be considered both as predictors and outcomes in this study. While they can increase as a result of intraoperative complications (i.e. bladder perforation), they can also influence the risk of postoperative complications (i.e. urinary tract infection, pneumonia, embolism, etc.). Finally, due to the large number of analyses, bias resulting from accidental observations might appear.

In conclusion, TURBT poses a significant risk of surgical complications, the majority of which are of low grade. The most significant, clinically sound predictors of TURBT complications are high ASA score, history of nicotine abuse, high-grade tumour, high-stage tumour, presence of muscularis propria in the specimen, and the resident surgeon. Proper preoperative identification of patients at high risk of complication may further reduce this risk if the surgery is performed carefully by an experienced surgeon.

\section{Acknowledgments}

All procedures performed in studies involving human participants were in accordance with the ethical standards of the institutional and/or national research committee and with the 1964 Helsinki declaration and its later amendments or comparable ethical standards. Informed consent was obtained from all individual participants. The protocol was registered within ClinicalTrials. gov (NCT03029663) and was approved by the Institutional Review Board of Warsaw Medical University.

Informed consent was obtained from all individual participants.

The data used to support the findings of this study are available from the corresponding author upon request.

\section{Conflict of interest}

The authors declare no conflict of interest.

\section{References}

1. Svatek RS, Hollenbeck BK, Holmäng $S$, et al. The economics of bladder cancer: costs and considerations of caring for this disease. Eur Urol 2014; 66: 253-62.

2. Lee F, Patel HR, Emberton M. The 'top 10' urological procedures: a study of hospital episodes statistics 1998-99. BJU Int 2002; 90: 1-6.

3. Brausi M, Collette L, Kurth K, et al. Variability in the recurrence rate at first follow-up cystoscopy after TUR in stage Ta T1 transitional cell carcinoma of the bladder: a combined analysis of seven EORTC studies. Eur Urol 2002; 41: 523-31

4. Zhang KY, Xing JC, Li W, Wu Z, Chen B, Bai DY. A novel transurethral resection technique for superficial bladder tumor: retrograde en bloc resection. World J Surg Oncol 2017; 15: 125.

5. Bansal A, Sankhwar S, Goel A, Kumar M, Purkait B, Aeron R. Grading of complications of transurethral resection of bladder tumor using Clavien-Dindo classification system. Indian J Urol 2016; 32: 232-7.

6. Gregg JR, McCormick B, Wang L, et al. Short term complications from transurethral resection of bladder tumor. Can J Urol 2016; 23: 8198-203.

7. De Nunzio C, Franco G, Cindolo L, et al. Transuretral resection of the bladder (TURB): analysis of complications using a modified Clavien system in an Italian real life cohort. Eur J Surg Oncol 2014; 40: 90-5.

8. Pycha A, Lodde M, Lusuardi L, et al. Teaching transurethral resection of the bladder: still a challenge? Urology 2003; 62: 46-8.

9. Collado A, Chechile GE, Salvador J, Vicente J. Early complications of endoscopic treatment for superficial bladder tumors. J Urol 2000; 164: 1529-32.

10. Team RC. A language and environment for statistical computing. Vienna, Austria 2017.

11. Summerton DJ, Kitrey ND, Lumen N, Serafetinidis E, Djakovic N; European Association of Urology. EAU guidelines on iatrogenic trauma. Eur Urol 2012; 62: 628-39.

12. Skolarikos A, Chrisofos M, Ferakis N, Papatsoris A, Dellis A, Deliveliotis C. Does the management of bladder perforation during transurethral resection of superficial 
S. Poletajew, W. Krajewski, D. Gajewska, J. Sondka-Migdalska, M. Borowik, P. Buraczyński, M. Dzięgała, M. Łykowski, M. Przudzik, A. Tukiendorf, R. Woźniak, K. Bar, Z. Jabłonowski, M. Roslan, M. Słojewski, R. Zdrojowy, P. Radziszewski, K. Dziobek

bladder tumors predispose to extravesical tumor recurrence? J Urol 2005; 173: 1908-11.

13. Mydlo JH, Weinstein R, Shah S, Solliday M, Macchia RJ. Long-term consequences from bladder perforation and/ or violation in the presence of transitional cell carcinoma: results of a small series and a review of the literature. J Urol 1999; 161: 1128-32.

14. Babjuk M, Bohle A, Burger $M$, et al. EAU guidelines on non-muscle-invasive urothelial carcinoma of the bladder: update 2016. Eur Urol 2017; 71: 447-61.

15. Bos D, Allard CB, Dason S, Ruzhynsky V, Kapoor A Shayegan B. Impact of resident involvement in endoscopic bladder cancer surgery on pathological outcomes. Scand J Urol 2016; 50: 234-8.

16. Rouprêt $M$, Yates DR, Varinot J, et al. The presence of detrusor muscle in the pathological specimen after transurethral resection of primary pT1 bladder tumors and its relationship to operator experience. Can J Urol 2012; 19: 6459-64.

17. Huang J, Fu J, Zhan $\mathrm{H}$, et al. Analysis of the absence of the detrusor muscle in initial transurethral resected specimens and the presence of residual tumor tissue. Urol Int 2012; 89: 319-25.

18. Mariappan P, Finney SM, Head E, et al. Good quality white-light transurethral resection of bladder tumours (GQ-WLTURBT) with experienced surgeons performing complete resections and obtaining detrusor muscle reduces early recurrence in new non-muscle-invasive bladder cancer: validation across time and place and recommendation for benchmarking. BJU Int 2012; 109: 1666-73.

19. Shoshany O, Mano R, Margel D, Baniel J, Yossepowitch O. Presence of detrusor muscle in bladder tumor specimens - predictors and effect on outcome as a measure of resection quality. Urol Oncol 2014; 32: 40.e17-22.

20. Balbay MD, Cimentepe E, Unsal A, Bayrak O, Koc A, Akbulut $Z$. The actual incidence of bladder perforation following transurethral bladder surgery. J Urol 2005; 174 2260-2, discussion 2262-3.

21. Hollenbeck BK, Miller DC, Taub D, et al. Risk factors for adverse outcomes after transurethral resection of bladder tumors. Cancer 2006; 106: 1527-35.

22. Picozzi S, Marenghi C, Ricci C, Bozzini G, Casellato S, Carmignani L. Risks and complications of transurethral resection of bladder tumor among patients taking antiplatelet agents for cardiovascular disease. Surg Endosc 2014; 28: 116-21

23. Carmignani L, Picozzi S, Stubinski R, et al. Endoscopic resection of bladder cancer in patients receiving double platelet antiaggregant therapy. Surg Endosc 2011; 25: 2281-7.

24. Konishi T, Washino S, Nakamura Y, et al. Risks and complications of transurethral resection of bladder tumors in patients receiving antiplatelet and/or anticoagulant therapy: a retrospective cohort study. BMC Urol 2017; 17: 118.

25. Dagli R, Dadali M. Methods to prevent development of adductor muscle contraction during transurethral resection of lateral bladder wall tumors. Arch Med Sci Civil Dis 2018; 3: e64-9.

26. Cui Y, Chen H, Liu L, Chen J, Qi L, Zu X. Comparing the efficiency and safety of bipolar and monopolar transurethral resection for non-muscle invasive bladder tumors: a systematic review and meta-analysis. J Laparoendosc Adv Surg Tech A 2016; 26: 196-202.

27. Zhao C, Tang K, Yang H, Xia D, Chen Z. Bipolar versus monopolar transurethral resection of nonmuscle-inva- sive bladder cancer: a meta-analysis. J Endourol 2016; 30: 5-12.

28. Balci M, Tuncel A, Keten T, et al. Comparison of monopolar and bipolar transurethral resection of non-muscle invasive bladder cancer. Urol Int 2018; 100: 100-4.

29. Ozer K, Horsanali MO, Gorgel SN, Ozbek E. Bladder injury secondary to obturator reflex is more common with plasmakinetic transurethral resection than monopolar transurethral resection of bladder cancer. Cent European J Urol 2015; 68: 284-8.

30. Bolat D, Aydogdu O, Tekgul ZT, et al. Impact of nerve stimulator-guided obturator nerve block on the shortterm outcomes and complications of transurethral resection of bladder tumour: a prospective randomized controlled study. Can Urol Assoc J 2015; 9: E780-4. 